\title{
Resolución laparoscópica de un caso de "Candy Cane" en un postoperatorio de By Pass Gástrico
}

Laparoscopic resolution of a case of "Candy Cane" in a postoperative period of

\section{Gastric Bypass}

Resolução laparoscópica de um caso de "Candy Cane" em pós-operatório de Bypass Gástrico

Martín Varela Vega ${ }^{1}$

ORCID 0000-0003-2376-2844

martinvarelav@gmail.com

DOI 10.31837/cir.urug/6.1.3

Gerardo Beraldo ${ }^{2}$

ORCID 0000-0002-3311-160X

gerardoberaldo@gmail.com

Pablo Santiago ${ }^{3}$

ORCID 0000-0002-7733-8291

friosanpab@yahoo.com

Sofía Baranov ${ }^{4}$

ORCID 0000-0002-1914-3285

sofibaranov@gmail.com

Agustina Da Rosa ${ }^{5}$

ORCID 0000-0002-7313-1306

agusdarosa@hotmail.com

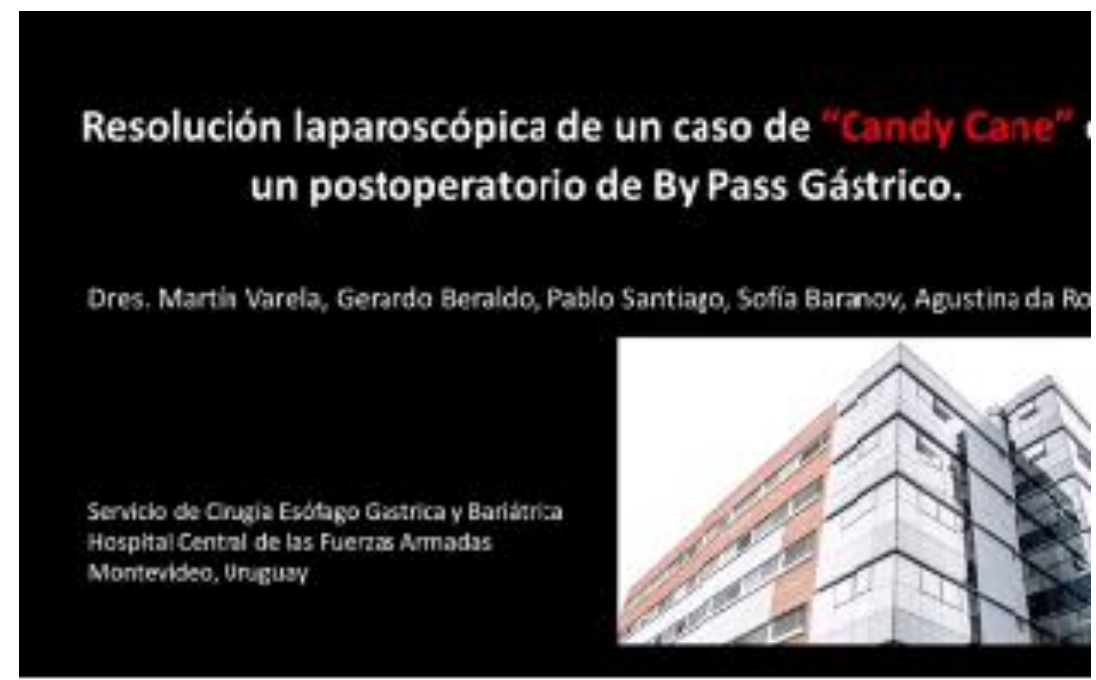

Recibido: 5 de mayo de 2021

Aceptado: 25 de noviembre de 2021

1,2,3,4,5. Servicio de Cirugía Bariátrica y Metabólica. Hospital Central de las Fuerzas Armadas. Montevideo, Uruguay. 


\section{Introducción}

El by pass gástrico (BPG) es una técnica de cirugía bariátrica de probada eficacia en el control de la obesidad y la resolución de enfermedades asociadas, como diabetes e hipertensión. El dolor abdominal en el postoperatorio alejado del BPG es un verdadero desafío, y exige para su diagnóstico etiológico comprender la técnica quirúrgica y las posibles causas que originan el dolor. Las principales causas de dolor son la úlcera de neoboca, las hernias internas (por el espacio de Petersen o la brecha mesentérica), la litiasis vesicular sintomática y el síndrome del "bastón de caramelo" (o "Candy Cane syndrome" por su nombre anglosajón). El mismo resulta de una excesiva longitud del cabo yeyunal ciego del asa alimentaria, luego de la anastomosis gastro yeyunal. Cuando mide más de $4 \mathrm{~cm}$ puede llenarse de alimentos, actuando como una bolsa o reservorio, generando dolor, náuseas o vómitos. El diagnóstico surge de la clínica y un estudio contrastado que demuestre la longitud excesiva del extremo del asa alimentaria. El tratamiento es quirúrgico y la desaparición de los síntomas confirma el diagnóstico.

\section{Objetivos}

Describir la exploración por vía laparoscópica de un paciente postoperatorio alejado de BPG con dolor abdominal y resolución quirúrgica laparoscópica de un síndrome de Candy Cane.

\section{Métodos}

Presentación de un video de seis minutos.

\section{Resultados}

Mujer de 55 años que en octubre de 2019 se realizó un BPG por obesidad y reflujo. Buen descenso posterior de peso. En diciembre de 2019 se realizó colecistectomía por litiasis vesicular sintomática. En abril de 2020 consulta por dolor epigástrico, vómitos y eructos. Peso actual 81 k. La endoscopía digestiva descarta úlcera de neoboca. La tomografía no muestra hernia interna evidente, pero se decide realizar laparoscopía exploradora. Durante la misma se verifica el espacio de Petersen abierto y permeable (se cierra) y la presencia de un Candy Cane que puede explicar el cuadro. Se realiza la resección del mismo con máquina de sutura lineal cortante. Buena evolución postoperatoria con desaparición del dolor abdominal. 


\section{Conclusiones}

El síndrome de Candy Cane es infrecuente pero debe tenerse en cuenta ante pacientes con dolor abdominal post BPG. Deben descartarse antes otras causas frecuentes, como la úlcera de neoboca, las hernias internas o la litiasis biliar.

\section{Referencias}

1. Aryaie AH, Fayezizadeh M, Wen Y, Alshehri M, Abbas M, Khaitan L. "Candy cane syndrome:" an underappreciated cause of abdominal pain and nausea after Roux-en-Y gastric bypass surgery. Surg Obes Relat Dis. 2017 Sep;13(9):1501-1505. Doi:

10.1016/j.soard.2017.04.006

2. Khan, K., Rodriguez, R., Saeed, S., Persaud, A., \& Ahmed, L. (2018). A Case series of candy cane limb syndrome after laparoscopic Roux-en-Y gastric bypass. Journal of surgical case reports, 2018(10), rjy244. Doi: 10.1093/jscr/rjv244

3. Kamocka, A., McGlone, E.R., Pérez-Pevida, B. et al. Candy cane revision after Roux-en-Y gastric bypass. Surg Endosc 34, 2076-2081 (2020). Doi: 10.1007/s00464-019-06988-4 